\title{
Results of Reconstruction with Jejunal Pouch after Gastrectomy: Correlation with Gastrointestinal Motor Activity
}

\author{
Chikashi Shibata Tatsuya Ueno Masayuki Kakyou Makoto Kinouchi \\ Iwao Sasaki
}

Division of Biological Regulation and Oncology, Department of Surgery, Tohoku University Graduate School of

Medicine, Sendai, Japan

\section{Key Words}

Gastrointestinal motility · Jejunal pouch · Gastrectomy,

proximal $\cdot$ Gastrectomy, total

\begin{abstract}
Background/Aims: To investigate if restoration of esophago-intestinal or esophago-gastric continuity with a jejunal pouch after total or proximal gastrectomy has clinical benefits. Methods: We reviewed all relevant reports published after 1990 that dealt with the clinical results of reconstruction with a jejunal pouch after total and proximal gastrectomies and correlated those findings with results for gastrointestinal motility. Reports were chosen from a search of the literature using PubMed. Results: After total gastrectomy, the benefit of a jejunal J pouch interposition was not apparent compared to simple jejunal interposition; indeed, one trial concluded that simple interposition was better than pouch interposition in terms of food intake. In contrast, results with a jejunal J pouch during Roux-en-Y (RY) type reconstruction were better than with conventional RY reconstruction in terms of food intake, nutritional status, body weight (BW) and symptoms. Advantages were also shown for a jejunal pouch with an inverted $U$ shape interposed between the esophagus and residual stomach after proximal gastrectomy. Reconstruction using a jejunal pouch after proximal gastrectomy was better than esophagogastrostomy or simple jejunal interposition in terms of food intake, BW
\end{abstract}

and symptoms. There were not enough data to conclude any benefits of a jejunal J pouch between the gastric remnant and the duodenum after distal gastrectomy. Conclusions: Clinical results of restoration of intestinal continuity with a jejunal pouch after total and proximal gastrectomies may be attributed, at least in part, to the relationship between the motor activity of the gastric remnant, duodenum and jejunal pouch.

Copyright $\odot 2009$ S. Karger AG, Basel

\section{Introduction}

The incidence of early gastric cancer is increasing in Japan; patients with stage IA and IB gastric cancer according to the Japanese classification of gastric carcinoma [1] account for more than half of all patients with gastric cancer, and 5-year survival rates for stage IA and IB cancer are 93.4 and $87.0 \%$, respectively [2]. Therefore, curative operative procedures that do not impair a patient's quality of life (QOL) would be optimal.

Many techniques for the restoration of intestinal continuity after gastrectomy have been proposed, both to compensate for the lost function of the stomach and in attempts to prevent postgastrectomy syndromes. Reconstruction with a jejunal pouch as a gastric substitute has been used for more than 50 years [3-6]. This construction of a jejunal pouch has been proposed after both total and 


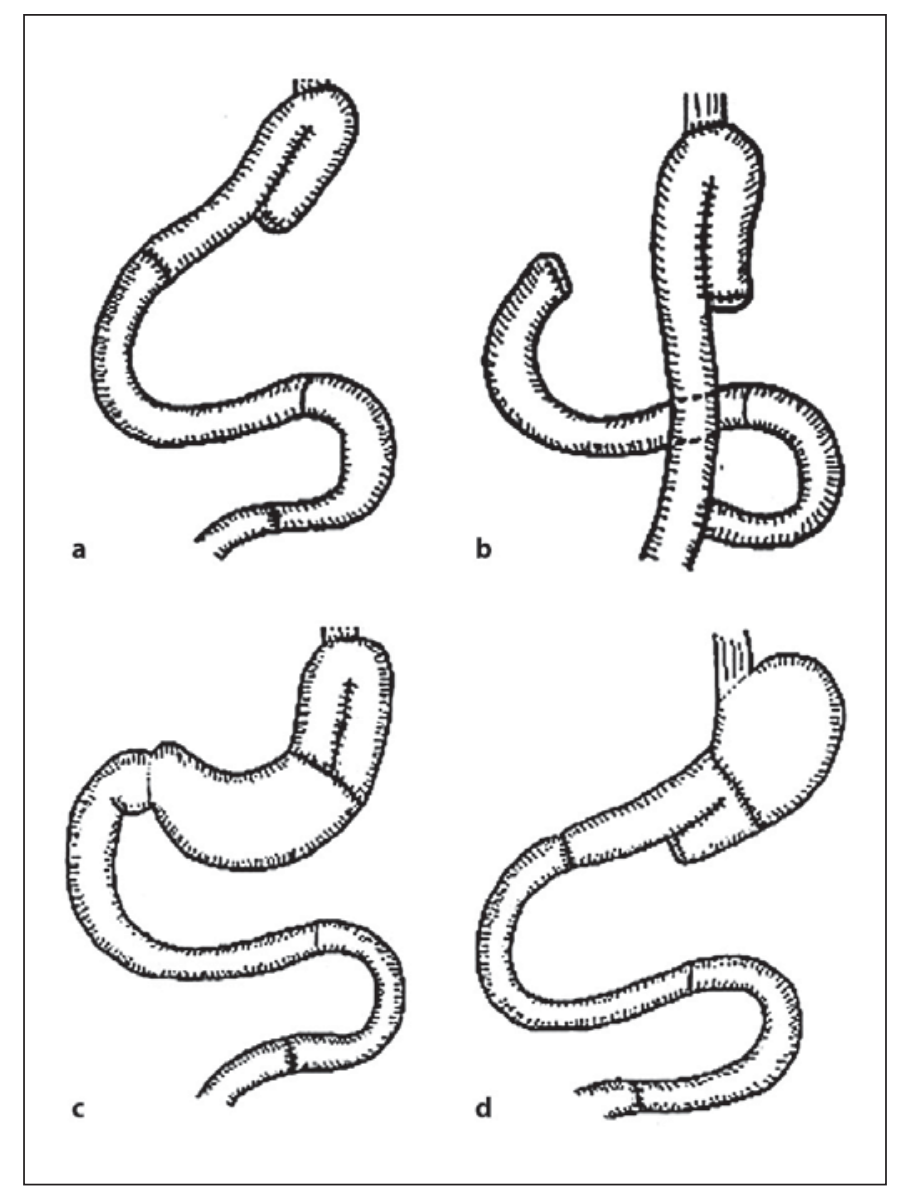

Fig. 1. Jejunal pouch reconstruction as a gastric substitute after total, proximal and distal gastrectomy. a JPI-T. b JPRY-T. c JPI-P. d JPI-D.

proximal gastrectomies and sometimes even after distal gastrectomy. Although the purpose of reconstruction with a jejunal pouch is to increase the storage capacity for ingested food, the benefits of this method of reconstruction are not yet obvious, and a jejunal pouch cannot be considered the standard reconstructive method. When surgeons create a jejunal pouch as a gastric substitute, they should consider the motor, exocrine and endocrine functions of the stomach and small intestine as they relate to the form of gastrectomy undertaken. The motor function of the stomach differs greatly between the proximal and distal stomach, and upper gastrointestinal motor activity differs between digestive (postprandial) and interdigestive (fasting) states. In the digestive state, food in the stomach is emptied into the duodenum by a very well-organized antro-pyloro-duodenal coordination. As far as we know, few attempts have been undertaken to interpret the clinical results after jejunal pouch reconstruction from the viewpoint of gastrointestinal motor physiology.

In this review, we present an overview of the physiology of upper gastrointestinal motor activity and the clinical results of reconstruction utilizing a jejunal pouch after total, proximal and distal gastrectomies. The aims of our present study were (1) to investigate if reconstruction with a jejunal pouch has clinical benefit in terms of patients' symptoms, body weight (BW), eating habits, nutritional status and overall QOL and (2) to correlate these results with the motor activity of the upper gastrointestinal tract.

\section{Methods}

We searched on PubMed for reports after 1990 dealing with clinical results with a jejunal pouch reconstruction after total, proximal or distal gastrectomy. Keywords for this search were gastrectomy and jejunal pouch. We judged results to be 'better' only when specific comparisons reached statistical significance; when $p$ values were not shown or only a tendency was described, the comparisons were considered as showing 'no difference'. The effect of the pouch was regarded as 'positive' when at least one investigated factor was better in the pouch group and as 'negative' when all factors studied were not different from or worse than the control group.

\section{Total Gastrectomy}

We summarized the clinical results of the 2 most representative reconstructions using a jejunal pouch (inverted J shape) after total gastrectomy: jejunal pouch interposition between the esophagus and the duodenum (JPI-T; fig. 1a) and Roux-en-Y (RY) type reconstruction with a jejunal pouch between the esophagus and the jejunum (JPRY-T; fig. 1b). In most reports, a jejunal pouch with an inverted J shape was used; however, several papers evaluated a jejunal S pouch reconstruction. We excluded papers that (1) investigated the appropriate size or length of the pouch, (2) reported techniques leaving the sphincter or creating a neo-sphincter and (3) described results after total and subtotal gastrectomy together as one group. We also excluded reports in which the jejunal pouch was created at the site of the jejunojejunostomy (pouch created using a long side-to-side jejunojejunostomy) during conventional RY reconstruction.

\section{Proximal Gastrectomy}

We reviewed the clinical results of reconstruction in which an inverted, U-shaped jejunal pouch was interposed between the esophagus and remnant stomach (JPI-P; fig. 1c).

\section{Distal Gastrectomy}

We also reviewed the clinical results of reconstruction in which a jejunal pouch with an inverted J shape was interposed between the gastric remnant and the duodenum (JPI-D; fig. 1d). 


\section{Results}

\section{Gastroduodenal Motor Pattern and Postprandial}

\section{Gastric Emptying}

In dogs, the physiology of gastrointestinal motility has been well documented, including diurnal changes in motor patterns. The motor physiology of the canine stomach is very similar to that of the human stomach [7]. Patterns of motor activity of the stomach and small intestine in dogs are largely divided into digestive and interdigestive states; indeed, very similar patterns are recognized in humans $[8,9]$.

Figure 2 shows the motor activity of the upper gastrointestinal tract in a dog. In the interdigestive state before feeding, a band of strong contractions migrating from the gastric body to the upper jejunum occurs at regular intervals of 90-120 min. This cyclic pattern of motor activity in the interdigestive state has been referred to as the migrating motor complexes (MMCs) [10, 11]. The role of these high-amplitude, peristaltic MMC contractions is believed to be to propel undigested solid foods distally to prepare for the next meal [12]. There is a distally oriented, decreasing gradient in peak amplitude and frequency of interdigestive contractions that occurs from the duodenum to the jejunoileum; these gradients contribute to aboral propulsions of intraluminal contents in the small intestine, and coordinated contractions in the antrum propel gastric content across the pylorus [13].

With feeding, the MMCs are interrupted and motor activity in the stomach and small intestine changes into a digestive pattern. In the proximal stomach, a vagally mediated decrease in baseline tone occurs after feeding (fig. 2), referred to as 'receptive relaxation' and 'gastric accommodation'. This proximal gastric relaxation serves to receive the bolus of ingesta from the esophagus and to accept increasing intragastric volumes without increasing intragastric pressure substantially. In contrast, regular and continuous phasic postprandial peristaltic contractions are observed in the gastric antrum, duodenum and jejunum (fig. 2). The postprandial gastro-pyloro-duodenal contractile pattern is divided into 3 phases: 'early' (the first 20-30 min after feeding), 'intermediate' (from 20-30 to 90-120 min after feeding) and 'late' (6-8 h after the intermediate phase) (fig. 3) [14].

These 3 phases of the postprandial motor pattern are closely associated with gastric emptying. The patterns of gastric emptying of liquids, digestible solids and indigestible solids are very different [15]. Liquid is emptied by the gradient in pressure which develops between the stomach and the duodenum primarily during the early

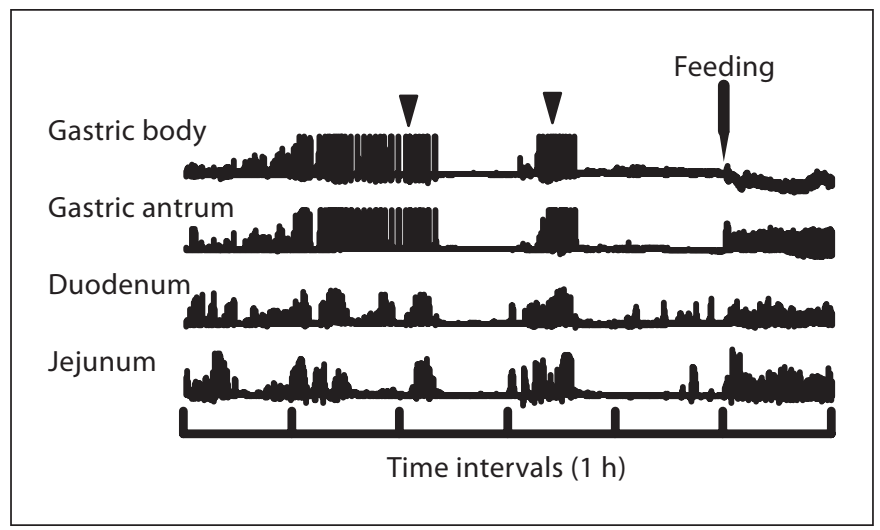

Fig. 2. Representative tracing of upper gastrointestinal motility in dogs. The motor activity of the upper gastrointestinal tract can be divided into two patterns, i.e., the interdigestive (fasting) and the digestive (postprandial) patterns. In the interdigestive state before feeding, cyclic changes in motor activity are observed at 90to 120 -min intervals. Arrowheads indicate a band of high-amplitude contractions, i.e. the MMCs. With feeding, this cyclic change in motility was disrupted temporarily. Receptive relaxation (decrease of tone) to store food without increasing intragastric pressure was identified in the gastric body, while continuous contractions appeared in the gastric antrum, duodenum and jejunum.

and intermediate phases (fig. 3). During the intermediate phase, solids are ground or triturated into small particles (less than $1 \mathrm{~mm}$ ) within the stomach by gastric antral contractions, the so-called antro-pyloric pump. While part of these triturated small particles empties from the stomach across the pylorus, the particles greater than $1 \mathrm{~mm}$ are retropulsed back into the more proximal stomach, become suspended in the liquid phase of the gastric content and may empty with the liquid [15]. Digestible solids remaining in the stomach after the early and intermediate phases are effectively and actively emptied by contractions in the gastric antrum synchronized with pyloric relaxations and duodenal contractions (antro-pyloro-duodenal coordination) during the late phase (fig. 3). Indigestible solids which remain in the stomach despite all these emptying processes are emptied with the very high-amplitude MMC contractions that occur in the antrum thereafter during restoration of the interdigestive state [15].

\section{Results of Jejunal Pouch Reconstruction after Total Gastrectomy}

Construction of a jejunal J pouch after total gastrectomy involves the proximal 'folded' portion (proximal pouch) and distal straight portion (distal conduit); the 


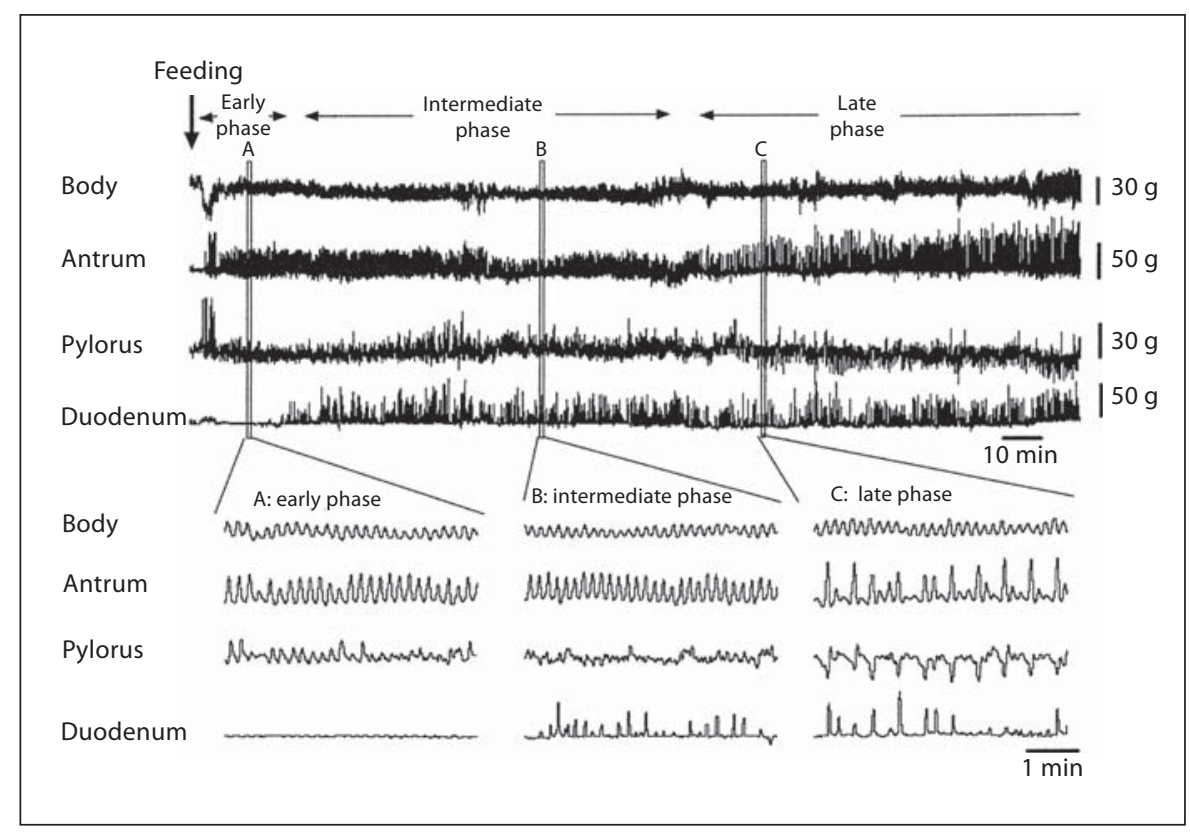

Fig. 3. A tracing showing the 3 phases of the upper gastrointestinal motor pattern after feeding (from Ueno et al. [14] with permission). Liquid is emptied by the pressure gradient between the stomach and duodenum during the early-intermediate phase. During the intermediate phase, intraluminal solids are triturated into small particles within the stomach by the antral contractions directed toward the pylorus. Because the pylorus is generally 'closed' in the intermediate phase, the small particles of less than
$1 \mathrm{~mm}$ empty from the stomach across the pylorus, while the larger particles are repelled back into the stomach. Some of the small particles become suspended in the liquid phase of the gastric content and empty with the liquid. Digestible solids remaining in the stomach after the early and intermediate phases are effectively and actively emptied by contraction in the gastric antrum synchronized with pyloric and proximal duodenal relaxation (gastro-pyloro-duodenal coordination) during the late phase. length of these two portions varies from 7 to $23 \mathrm{~cm}$ and from 10 to $33 \mathrm{~cm}$, respectively [16-21].

We found 5 papers that compared clinical results using a JPI-T with those using a straight jejunal interposition (JI-T; table 1). Two studies suggested a benefit with JPI-T, while 3 studies found no benefits. The earliest report retrospectively compared the results across 5 reconstruction types including JPI-T and JI-T and concluded that the jejunal pouch had no advantage with regard to BW and total protein (TP); however, the number of patients evaluated was not satisfactory [21]. Two randomized, controlled trials (RCTs) were published by the same group [19, 22]; the later report in 2002 [22] had more patients and concluded that the clinical results in patients with JPI-T were superior to those with JI-T in terms of eating habits (change in food consumption pattern and number of meals daily) and global health status as examined by the questionnaire validated by the European Organization for Research and Treatment of Cancer. However, the BW and the degree of each symptom examined in the European Organization for Research and
Treatment of Cancer questionnaire did not differ between the groups [22]. In another RCT, Tono et al. [20] found that JPI-T had advantages in terms of BW and TP, but at the same time, patients with JPI-T had more symptoms than those with JI-T. Taken together, these studies suggest that reconstruction with JPI-T has advantages with regard to eating habits, $\mathrm{BW}$ and $\mathrm{TP}$, but patients with JPI-T tend to have more symptoms compared to those with JI-T. It should be noted that Mochiki et al. [23] found that patients with a JI-T had better food consumption than patients with a JPI-T, suggesting that the reconstruction using an interposition pouch was detrimental.

There were 9 studies that compared results after the use of a JPRY-T with conventional RY (RY-T; table 2), 4 of which used a jejunal S pouch reconstruction [24-27]. These 4 studies failed to find any advantage of JPRY-T when assessed less than 1 year postoperatively; however, when assessed 3 years postoperatively, the JPRY-T was better in terms of nutrition and symptoms. Bozzetti et al. [28] reported that there were no differences in BW and 
Table 1. Summary of studies comparing JPI-T with JI-T

\begin{tabular}{|c|c|c|c|c|c|c|}
\hline Report & Year & $\begin{array}{l}\text { Trial } \\
\text { type }\end{array}$ & $\begin{array}{l}\text { Reconstruction types } \\
\text { (number of patients) }\end{array}$ & $\begin{array}{l}\text { Longest } \\
\text { follow-up } \\
\text { period }\end{array}$ & Results & $\begin{array}{l}\text { Benefit } \\
\text { of pouch }\end{array}$ \\
\hline $\begin{array}{l}\text { de Almeida } \\
\text { et al. [21] }\end{array}$ & 1994 & non-RCT & $\begin{array}{l}\text { JPI-T }^{1}(5), \text { JI-T (6), JPRY-T (5), } \\
\text { RY-T (46), omega }^{2}(2)\end{array}$ & 15 years & no difference in BW and TP between groups & negative \\
\hline $\begin{array}{l}\text { Hoksch } \\
\text { et al. [19] }\end{array}$ & 1999 & RCT & JPI-T (19), JI-T (8) & 1 year & no difference in eating habits & negative \\
\hline $\begin{array}{l}\text { Hoksch } \\
\text { et al. [22] }\end{array}$ & 2002 & RCT & JPI-T (28), JI-T (13) & 1 year & $\begin{array}{l}\text { better eating habits and global health status } \\
\text { with JPI-T; no difference in BW and symptoms } \\
\text { assessed by the EORTC questionnaire (QLQ-C30) }\end{array}$ & positive \\
\hline $\begin{array}{l}\text { Tono } \\
\text { et al. [20] }\end{array}$ & 2003 & non-RCT & JPI-T (11), JI-T (9) & 2 years & $\begin{array}{l}\text { better BW and TP with JPI-T; } \\
\text { more symptoms with JPI-T }\end{array}$ & positive \\
\hline $\begin{array}{l}\text { Mochiki } \\
\text { et al. [23] }\end{array}$ & 2004 & RCT & JPI-T (14), JI-T (12) & 58 months & better food consumption with JI-T & negative \\
\hline
\end{tabular}

EORTC $=$ European Organization for Research and Treatment of Cancer.

${ }^{1}$ The pouch was a modified Kock's pouch. ${ }^{2}$ A Braun (omega) loop anastomosis.

eating habits between these 2 groups but that after JPRY-T, there were less gastrointestinal symptoms; although they concluded that there was no substantive benefit of pouch reconstruction, we classified their results as 'positive' according to our definition. The remaining 4 studies showed a benefit with JPRY-T in terms of eating capacity, food intake, BW, nutrition and symptoms [29-32]. When considered together, these 9 studies suggest that the postoperative results of JPRY-T are generally more favorable than those of RY-T.

Six reports compared the clinical results of JPI-T with those of JPRY-T (table 3); 3 studies compared JPI-T with JPRY-T, while the 3 remaining studies compared JPI-T, JPRY-T and RY-T. The comparisons of JPI-T and JPRY-T found no differences in symptoms, BW and QOL [17, 33, 34]. Nakane et al. [16] reported that after JPRY-T, a benefit was noted in terms of symptoms, food intake and BW recovery compared to JPI-T and RY-T. Schwarz et al. [18] found that the postoperative QOL as assessed by life quality score was greater with JPI-T than with JRY-T and RY-T. They also found that hormone secretion (insulin, cholecystokinin, motilin and pancreatic polypeptide) was more 'physiologic' after JPI-T than after the other 2 types of reconstruction; despite these findings, no differences in BW were observed amongst the 3 groups. Adachi et al. [35] suggested a long-term advantage of pouch reconstruction, because the results after JPRY-T were good in the first 3 years postoperatively, while the results after JPI-T were better after 3 years postoperatively. Overall, although the use of a J pouch for reconstruction seems beneficial, it remains difficult to suggest which type of pouch reconstruction (JPI-T or JPRY-T) is superior in terms of postoperative QOL.

\section{Results of Jejunal Pouch Reconstruction after Proximal Gastrectomy}

Six studies evaluated the clinical results after JPI-P (table 4). Five studies found benefits with a jejunal pouch reconstruction, while 1 study was negative. As a control group for comparison with JPI-P, we believe that esophagogastrostomy or simple jejunal interposition between the esophagus and the remnant stomach (JI-P) would be appropriate. One non-RCT showed that JPI-P was better than JI-P in terms of gastrointestinal symptoms, BW and TP [36]. One RCT found that JPI-P was superior to JI-P in terms of food intake and BW; however, we judged the benefit of the pouch in this report as 'negative,' because $p$ values were greater than 0.05 [37]. When JPI-P was compared with esophagogastrostomy, 1 study [38] found that food intake was greater after JPI-P, and gastrointestinal symptoms were fewer with JPI-P than esophagogastrostomy, while the other study reported no benefit of JPI-P [39]. These results indicate that the JPI-P reconstruction appears to have advantages in comparison with JI-P, while any benefit of JPI-P compared with esophagogastrostomy remains uncertain. It should be noted that the 
Table 2. Summary of studies comparing JPRY-T with RY-T

\begin{tabular}{|c|c|c|c|c|c|c|}
\hline Report & Year & $\begin{array}{l}\text { Trial } \\
\text { type }\end{array}$ & $\begin{array}{l}\text { Reconstruction types } \\
\text { (number of patients) }\end{array}$ & $\begin{array}{l}\text { Longest } \\
\text { follow-up } \\
\text { period }\end{array}$ & Results & $\begin{array}{l}\text { Benefit } \\
\text { of pouch }\end{array}$ \\
\hline $\begin{array}{l}\text { Bozzetti } \\
\text { et al. [28] }\end{array}$ & 1996 & RCT & JPRY-T (15), RY-T (12) & 2 years & $\begin{array}{l}\text { no difference in BW, eating habits, TP and albumin; } \\
\text { improvement in symptoms with JPRY-T }\end{array}$ & positive \\
\hline $\begin{array}{l}\text { Liedman } \\
\text { et al. [24] }\end{array}$ & 1996 & RCT & $\begin{array}{l}\text { JPRY-T }{ }^{1}(28), \text { RY-T (49), } \\
\text { SG (12) }\end{array}$ & 1 year & $\begin{array}{l}\text { improvement in symptoms with RY-T; no difference in energy } \\
\text { intake and BW }\end{array}$ & negative \\
\hline $\begin{array}{l}\text { Svedlund } \\
\text { et al. [25] }\end{array}$ & 1997 & RCT & $\begin{array}{l}\text { JPRY-T }{ }^{1}(20), \text { RY-T (31), } \\
\text { SG (13) }\end{array}$ & 1 year & better QOL with SG compared to JPRY-T and RY-T & negative \\
\hline $\begin{array}{l}\text { Liedman } \\
\text { et al. [26] }\end{array}$ & 1998 & RCT & JPRY-Tํㅣ (13), RY-T (23) & over 3 years & $\begin{array}{l}\text { improvement in BW and loss of fat stores with JPRY-T; } \\
\text { no difference in food intake. }\end{array}$ & positive \\
\hline $\begin{array}{l}\text { Svedlund } \\
\text { et al. [27] }\end{array}$ & 1999 & RCT & $\begin{array}{l}\text { JPRY-T }{ }^{1}(20), \text { RY-T (31), } \\
\text { SG (13) }\end{array}$ & 5 years & $\begin{array}{l}\text { improvement in indigestion symptoms assessed by GSRS score } \\
\text { with JPRY-T }\end{array}$ & positive \\
\hline $\begin{array}{l}\text { Iivonen } \\
\text { et al. [29] }\end{array}$ & 2000 & RCT & JPRY-T (20), RY-T (14) & 8 years & $\begin{array}{l}\text { improvement in eating capacity, dumping, early satiety and BW } \\
\text { loss with JPRY-T at } 3 \text { years after surgery, but no difference at } 8 \text { years }\end{array}$ & positive \\
\hline $\begin{array}{l}\text { Miyoshi } \\
\text { et al. [30] }\end{array}$ & 2001 & non-RCT & JPRY-T (22), RY-T (12) & 2 years & $\begin{array}{l}\text { improvement in eating capacity, QOL assessed by GSRS score } \\
\text { and reflux symptoms with JPRY-T; no change in number of meals } \\
\text { per day and BW }\end{array}$ & positive \\
\hline $\begin{array}{l}\text { Nozoe } \\
\text { et al. [31] }\end{array}$ & 2001 & non-RCT & JPRY-T (14), RY-T (16) & 2 years & $\begin{array}{l}\text { improvement in BW and serum albumin at } 1 \text { year and in } \\
\text { prognostic nutritional index ratio at } 1 \text { and } 3 \text { months with JPRY-T; } \\
\text { no difference in heartburn and BW }\end{array}$ & positive \\
\hline $\begin{array}{l}\text { Kono } \\
\text { et al. [32] }\end{array}$ & 2003 & RCT & JPRY-T (23), RY-T (24) & $3-48$ months & $\begin{array}{l}\text { improvement in food intake, QOL assessed by GSRS score, } \\
\text { BW and bile regurgitation with JPRY-T; no difference in TP, } \\
\text { albumin and hemoglobin }\end{array}$ & positive \\
\hline
\end{tabular}

SG = Subtotal gastrectomy; GSRS = Gastrointestinal Symptom Rating Scale .

${ }^{1}$ Jejunal $S$ pouch.

jejunal pouch was extremely dilated in some patients after JPI-P and a reoperation was often necessary in this condition [40, 41].

\section{Results of Jejunal Pouch Reconstruction after Distal Gastrectomy}

Although several papers described the technique of reconstruction using a JPI-D [42, 43], there were only 2 reports that retrospectively studied the postoperative results after JPI-D. Miwa et al. [44] performed JPI-D in 101 patients and compared the clinical outcome with the results in 64 patients who underwent distal gastrectomy and Billroth I reconstruction; the JPI-D reconstruction proved better in terms of the number of meals able to be ingested per day, dumping syndrome and symptoms of heartburn. Another group reported that JPI-D was better than simple jejunal interposition and Billroth I reconstruction in terms of food intake and symptoms of heartburn [45]. Thus, although advantages of reconstruction using a jejunal pouch interposition after distal gastrectomy have been reported, only 2 studies have been carried out, and both were retrospective reviews.

\section{Discussion}

When the postoperative results after JPI-T are compared with those after JI-T, the benefits of a pouch reconstruction remain controversial for several reasons; firstly, only 2 of the 5 studies concluded that JPI-T was beneficial, and even in those 2 reports, no differences were found in some of the factors evaluated such as gastrointestinal symptoms. Secondly, one RCT showed that food consumption was greater with JI-T than with JPI-T. In contrast, the benefit of a pouch during an RY reconstruction appears to be established; only 2 of 9 studies found no difference in clinical outcomes when JPRY-T was compared to RY-T, while the more recent 6 studies in which patients with 
Table 3. Summary of studies comparing JPI-T with JPRY-T

\begin{tabular}{|c|c|c|c|c|c|c|c|}
\hline Report & Year & $\begin{array}{l}\text { Trial } \\
\text { type }\end{array}$ & $\begin{array}{l}\text { Reconstruction types } \\
\text { (number of patients) }\end{array}$ & $\begin{array}{l}\text { Longest } \\
\text { follow-up } \\
\text { period }\end{array}$ & Results & $\begin{array}{l}\text { Benefit } \\
\text { of pouch }\end{array}$ & $\begin{array}{l}\text { Which } \\
\text { pouch is } \\
\text { better }\end{array}$ \\
\hline $\begin{array}{l}\text { Nakane } \\
\text { et al. [16] }\end{array}$ & 1995 & RCT & $\begin{array}{l}\text { JPI-T (10), } \\
\text { JPRY-T (10), RY-T (10) }\end{array}$ & 64 months & $\begin{array}{l}\text { improvement in symptoms, food intake and BW } \\
\text { recovery with JPRY-T compared to JPI-T and RY-T }\end{array}$ & positive & JPRY-T \\
\hline $\begin{array}{l}\text { Fuchs } \\
\text { et al. [17] }\end{array}$ & 1995 & RCT & $\begin{array}{l}\text { JPI-T (53), } \\
\text { JPRY-T (53) }\end{array}$ & $\begin{array}{l}\text { over } \\
5 \text { years }\end{array}$ & $\begin{array}{l}\text { no difference in BW and QOL assessed by Visick score } \\
\text { and Spitzer index }\end{array}$ & - & no difference \\
\hline $\begin{array}{l}\text { Schwarz } \\
\text { et al. [18] }\end{array}$ & 1996 & RCT & $\begin{array}{l}\text { JPI-T (24), } \\
\text { JPRY-T (24), RY-T (12) }\end{array}$ & 6 months & $\begin{array}{l}\text { better QOL score, hormone secretion, serum iron } \\
\text { levels and hemoglobin with JPI-T; no difference in BW }\end{array}$ & positive & JPI-T \\
\hline $\begin{array}{l}\text { Nakane } \\
\text { et al. [33] }\end{array}$ & 2001 & RCT & $\begin{array}{l}\text { JPI-T (15), } \\
\text { JPRY-T (15) }\end{array}$ & $\begin{array}{l}\text { less than } \\
2 \text { years }\end{array}$ & $\begin{array}{l}\text { no difference in postprandial symptoms, food intake, } \\
\text { BW and nutritional parameters; food stasis with } \\
\text { JPRY-T but not significant }\end{array}$ & - & no difference \\
\hline $\begin{array}{l}\text { Adachi } \\
\text { et al. [35] }\end{array}$ & 2003 & RCT & $\begin{array}{l}\text { JPI-T (10), } \\
\text { JPRY-T (10), RY-T (10) }\end{array}$ & $\begin{array}{l}\text { over } \\
5 \text { years }\end{array}$ & $\begin{array}{l}\text { better in terms of heartburn, dumping and BW with } \\
\text { JPI-T and JPRY-T; better in terms of nutritional } \\
\text { evaluation with JPI-T than JPRY-T; better in terms of } \\
\text { nutrition risk index with JPI-T than RY-T }\end{array}$ & positive & $\begin{array}{l}\text { short term: } \\
\text { JPRY-T; long } \\
\text { term: JPI-T }\end{array}$ \\
\hline $\begin{array}{l}\text { Takeshita } \\
\text { et al. [34] }\end{array}$ & 2007 & non-RCT & JPI-T (12), JPRY-T (12) & 15 years & $\begin{array}{l}\text { no significant difference in symptoms between the } \\
2 \text { groups }\end{array}$ & - & no difference \\
\hline
\end{tabular}

JPRY-T were followed for more than 2 years concluded that JPRY-T was superior to RY-T in terms of gastrointestinal symptoms, QOL, eating capacity, BW and nutrition.

We believe that the motor activity of the jejunal pouch could account for this difference between JPI-T and JPRY$\mathrm{T}$. The jejunal pouches in JPI-T and JPRY-T are created in an attempt to compensate for the loss of the reservoir function of the proximal stomach. Although the jejunum does not have the ability to undergo 'receptive relaxation', contractile activity of the proximal, folded portion of the jejunal J pouch decreases due to the longitudinal transection performed during the creation of the pouch [23]. Therefore, the jejunal pouch appears to function as a reservoir at least to some extent. After a JPI-T, the 'distal conduit' of the jejunal pouch has to empty the food stored in the proximal part of the pouch into the duodenum, where the contractile activity (amplitude and frequency of contractions) is greater than in the jejunum. As we mentioned above during the discussion of the motor physiology of the upper gastrointestinal tract, the contractile force decreases progressively from the gastric antrum to the jejunum, and the frequency of contractions decreases from the duodenum to the jejunum, and this phenomenon is associated in part with the progressive transit of intraluminal contents in the aboral direction. Postprandial gastric emptying is very well organized in terms of the strong peristaltic contractions in the gastric antrum and is associated temporally with antro-pyloro-duodenal coordina- tion. It would not be expected that the distal conduit of the jejunal pouch would function similarly to the gastric antrum; indeed, the contractile activity of the distal jejunal conduit of the J pouch probably does not allow smooth pouch-duodenal emptying, and thus the pouch in JPI-T could act as a reservoir but with a poor emptying function. The situation is different with JPRY-T, because the distal jejunal conduit of the pouch does not have to empty food toward a site (duodenum) which has a greater inherent frequency and amplitude of contractions. Therefore, the transit of intraluminal contents after they leave the jejunal pouch after JPRY-T may be considered more 'physiologic' than after JPI-T. We hypothesize that the relatively poor 'emptying' of a JPI-T might lead to the higher incidence of postprandial gastrointestinal symptoms.

Although the results above suggest that JPRY-T seems advantageous compared to JPI-T, long-term postoperative results were not so different when direct comparisons were made between JPRY-T and JPI-T (table 3). A multicenter RCT comparing JI-T, JPI-T, RY-T and JPRY-T would help resolve this issue. Comparison between JPI-T and JPRY-T also begs the question of whether the passage of ingested content through the duodenum is important to maximize patients' QOL. Two review papers concluded that this 'duodenal passage' was not associated with improvement in postoperative QOL $[46,47]$.

With regard to proximal gastrectomy, most studies have reported that a JPI-P offers a benefit compared to a 
Table 4. Summary of results with JPI-P

\begin{tabular}{|c|c|c|c|c|c|c|}
\hline Report & Year & Trial type & $\begin{array}{l}\text { Reconstruction types } \\
\text { (number of patients) }\end{array}$ & $\begin{array}{l}\text { Longest } \\
\text { follow-up } \\
\text { period }\end{array}$ & Results & $\begin{array}{l}\text { Benefit } \\
\text { of pouch }\end{array}$ \\
\hline $\begin{array}{l}\text { Takeshita } \\
\text { et al. [50] }\end{array}$ & 1997 & non-RCT & $\begin{array}{l}\text { JPI-P (12), JI-P (UK), } \\
\text { JI-T (UK) }\end{array}$ & 2 years & $\begin{array}{l}\text { physiological in terms of gastric emptying } \\
\text { determined by radio-opaque markers }\end{array}$ & positive \\
\hline $\begin{array}{l}\text { Kameyama } \\
\text { et al. [36] }\end{array}$ & 2004 & non-RCT & JPI-P (59), JI-P (13) & 17 years & improvement in symptoms, BW and TP with JPI-P & positive \\
\hline $\begin{array}{l}\text { Yoo } \\
\text { et al. [51] }\end{array}$ & 2005 & RCT & JPI (25), RY-T (26) & 3 years & $\begin{array}{l}\text { better in terms of frequency of postgastrectomy } \\
\text { syndrome, food intake, BW, hemoglobin and vitamin } \\
\mathrm{B}_{12} \text { with JPI-P; no difference in TP and albumin }\end{array}$ & positive \\
\hline $\begin{array}{l}\text { Iwata } \\
\text { et al. [37] }\end{array}$ & 2006 & RCT & JPI-P (4), JI-P (5) & 3 months & $\begin{array}{l}\text { better food intake and BW } \\
\text { ( } \mathrm{p} \text { values greater than } 0.05 \text { ) }\end{array}$ & negative \\
\hline $\begin{array}{l}\text { Hoshikawa } \\
\text { et al. [38] }\end{array}$ & 2001 & non-RCT & JPI-P (21), EG (23) & 3 years & $\begin{array}{l}\text { improvement in BW and symptoms; no difference } \\
\text { in TP and albumin }\end{array}$ & positive \\
\hline $\begin{array}{l}\text { Okino } \\
\text { et al. [39] }\end{array}$ & 2008 & non-RCT & JPI-P (14), EG (22) & 10 years & $\begin{array}{l}\text { no difference in symptoms, food intake, BW and } \\
\text { nutrition; more food residue in JPI-P }\end{array}$ & negative \\
\hline
\end{tabular}

$\mathrm{UK}=$ Unknown; EG = esophagogastrostomy.

JI-P or esophagogastrostomy. The rationale for the use of a pouch is that it would help to restore the gastric reservoir function lost after proximal gastrectomy. The hepatic and celiac branches of the vagus nerves are often preserved after proximal gastrectomy [48], but the vagal innervation to the gastric antrum (nerves of Latarjet) is transected. If the postprandial, antro-pyloro-duodenal coordination is preserved after proximal gastrectomy, interposing a jejunal pouch between the esophagus and the distal gastric remnant as a reservoir would appear quite rational. One factor affecting antro-pyloro-duodenal coordination is the size of the gastric remnant. It is unknown whether transection of the gastric body at various levels and transection of the hepatic-pyloric, celiac or antral vagal branches alter postprandial antro-pyloro-duodenal coordination, and the effects of these and other variables during proximal gastrectomy will likely prove important.

We do not have enough data to conclude that JPI-D offers any clinical advantage. After distal gastrectomy, the reservoir function of the proximal stomach, although greatly impaired, still remains [10]. Therefore, JPI-D is designed to replace the emptying function of the gastric antrum lost after distal gastrectomy. As with JPI-T, it is unknown if the jejunum can empty food smoothly and effectively into the duodenum. More information is nec- essary to conclude that a JPI-D offers any clinical advantages over a Billroth I gastroduodenostomy.

Several factors other than motor activity are also considered to influence the function of the gastric remnant and the jejunal pouch, which may affect patients' symptoms. The degree of extrinsic denervation of the gastric remnant affects not only motor but also exocrine and endocrine functions. The length and volume of the jejunal pouch are also considered to be important factors for the function of the pouch $[16,49]$ and will require further investigation.

As seen in tables 1-4, the numbers of patients who underwent each type of reconstruction were less than 20 in many studies and about 50 at most, limiting the reliability of the conclusions. Because of difficulties with standardizing reconstructive techniques between institutions, performing a multicenter trial to acquire a statistically valid number of patients is never easy. Therefore, it is not possible to make strong conclusions based on the current literature about which types of reconstructive procedures are superior in terms of QOL. Another problem noted in the interpretation of the various outcomes is that that the primary end point(s) often varied across studies. There are many parameters used to assess global QOL, such as BW, eating capacity or eating habits, overall nutritional status, gastrointestinal symptoms and physi- 
cal functioning assessed by various scores; which of these measures of overall QOL are superior remains unknown. In addition, from the patient's perspective, the importance of any one parameter will likely vary between individuals.

We conclude that when compared to RY-T, JPRY-T offers benefits in terms of postoperative QOL as assessed by food intake, gastrointestinal symptoms and nutritional parameters, including BW. There was no obvious benefit of JPI-T when compared to JI-T. JPI-P may be advantageous compared to JI-P and esophagogastrostomy, but there were too few studies to reach any valid, evidence- based conclusions. When considered in the context of motor activity, we believe that many of the findings regarding pouch function can, at least in part, be attributed to the motor activity of the residual stomach, duodenum and jejunal pouch.

\section{Acknowledgement}

The authors thank Dr. Michael G. Sarr, Department of Surgery, Mayo Clinic and Foundation, Rochester, Minn., USA, for reviewing the manuscript.

\section{References}

1 Japanese Classification of Gastric Carcinoma, ed 13. Tokyo, Kanehara, 1999.

2 Treatment Guideline of Gastric Carcinoma, ed 2. Tokyo, Kanehara, 2004.

-3 Engel GC: The creation of a gastric pouch following total gastrectomy. Surgery 1945; 17:512.

4 Steinberg ME: A double jejunal lumen gastrointestinal anastomosis: pantaloon anastomosis. Surg Gynecol Obstet 1949;88:44534464.

5 Hunt CJ: Construction of food pouch from segment of jejunum as substitute for stomach in total gastrectomy. AMA Arch Surg 1952; 64:601-608.

6 Lawrence W Jr: Reservoir reconstruction after total gastrectomy. Ann Surg 1962;355; 191-198.

-7 El-Sharkawy TY, Morgan KG, Szurszewski $\mathrm{JH}$ : Intracelluar electrical activity of canine and human gastric smooth muscle. J Physiol 1978;279:291-307.

-8 Vantrappen G, Jannssens J, Hellemans J, Ghoos Y: The interdigestive motor complex of normal subjects and patients with bacterial overgrowth of the small intestine. J Clin Invest 1977;59:1158-1166.

9 Wingate DL: Small intestine; in Shuster MM (ed): Atlas of Gastrointestinal Motility in Health and Disease. Baltimore, Williams and Wilkins, 1993, pp 177-214.

10 Shibata C, Sasaki I, Naito H, et al: Gastrointestinal motor activity after pylorus-preserving gastrectomy with or without vagotomy in dogs. J Am Coll Surg 1995; 181: 545-551.

-11 Code CF, Marlett JA: The interdigestive myo-electric complex of the stomach and small bowel of dogs. J Physiol 1975;246:289309.

12 Mroz CT, Kelly KA: The role of the extrinsic antral nerves in the regulation of gastric emptying. Surg Gynecol Obstet 1977;145: 369-377.
13 Tanaka T, VanKlompenberg LH, Sarr MG: Selective role of vagal and nonvagal innervation in initiation and coordination of gastric and small bowel patterns of interdigestive and postprandial motility. J Gastrointest Surg 2001;5:414-433.

14 Ueno T, Uemura K, Harris MB, et al: Role of vagus nerve in postprandial antropyloric coordination in conscious dogs. Am J Physiol Gastrointest Liver Physiol 2005;288:G487G495.

15 Kelly KA: Gastric emptying of liquids and solids: roles of proximal and distal stomach Am J Physiol 1980;239:G71-G76.

16 Nakane Y, Okumura S, Akehira K, et al: Je junal pouch reconstruction after total gastrectomy for cancer: a randomized controlled trial. Ann Surg 1995;222:27-35.

17 Fuchs KH, Thiede A, Engemann R, et al: Reconstruction of the food passage after total gastrectomy: randomized trial. World J Surg 1995;19:698-706.

18 Schwarz A, Buchler M, Usinger K, et al: Importance of the duodenal passage and pouch volume after total gastrectomy and reconstruction with the Ulm pouch: prospective randomized clinical study. World J Surg 1996;20:60-67.

19 Hoksch B, Zieren HU, Muller JM: Regular scintigraphic measurements of food transit following different types of reconstruction after total gastrectomy. Arch Surg 1999;134: 1270-1273.

20 Tono C, Terashima M, Takagane A, Abe K: Ideal reconstruction after total gastrectomy by the interposition of a jejunal pouch considered by emptying time. World J Surg 2003 27:1113-1118.

21 de Almeida AC, dos Santos NM, Aldeia FJ: Total gastrectomy for cancer: is reconstruction or a gastric replacement reservoir essential? World J Surg 1994;18:883-888.
22 Hoksch B, Ablassmaier B, Zieren J, Muller JM: Quality of life after gastrectomy: Longmire's reconstruction alone compared with additional pouch reconstruction. World J Surg 2002;26:335-341.

-23 Mochiki E, Kamiyama Y, Aihara R, et al: Postoperative functional evaluation of jejunal interposition with or without a pouch after a total gastrectomy for gastric cancer. Am J Surg 2004;187:728-735.

24 Liedman B, Anderson H, Berglund B, et al: Food intake after gastrectomy for gastric carcinoma: the role of a gastric reservoir. $\mathrm{Br}$ J Surg 1996;83:1138-1143.

25 Svedlund J, Sullivan M, Liedman B, et al: Quality of life after gastrectomy for gastric carcinoma: controlled study of reconstructive procedures. World J Surg 1997;21:422433.

26 Liedman B, Bosaeus I, Hugosson I, Lundell L: Long-term beneficial effects of a gastric reservoir on weight control after total gastrectomy: a study of potential mechanisms. Br J Surg 1998;85:542-547.

27 Svedlund J, Sullivan M, Liedman B, Lundell L: Long term consequences of gastrectomy for patient's quality of life: the impact of reconstructive techniques. Am J Gastroenterol 1999;94:438-445.

28 Bozzetti F, Bonfanti G, Castellani R, et al: Comparing reconstruction with Roux-en-Y to a pouch following total gastrectomy. J Am Coll Surg 1996;183:243-248.

29 Iivonen MK, Mattila JJ, Nordback IH, Matikainen MJ: Long-term follow-up of patients with jejunal pouch reconstruction after total gastrectomy. Scand J Gastroenterol 2000;35: 679-685.

30 Miyoshi K, Fuchimoto S, Ohasaki T, et al: Long-term effects of jejunal pouch added to Roux-en-Y reconstruction after total gastrectomy. Gastric Cancer 2001;4:156-161. 
-31 Nozoe T, Anai H, Sugimachi K: Usefulness of reconstruction with jejunal pouch in total gastrectomy for gastric cancer in early improvement of nutritional condition. Am J Surg 2001;181:274-278.

- 32 Kono K, Iizuka H, Sekikawa T, et al: Improved quality of life with jejunal pouch reconstruction after total gastrectomy. Am J Surg 2003;185:150-154.

33 Nakane Y, Michiura T, Inoue K, et al: A randomized clinical trial of pouch reconstruction after total gastrectomy for cancer: which is the better technique, Roux-en-Y or interposition? Hepatogastroenterology 2001;48: 903-907.

-34 Takeshita K, Sekita Y, Tani M: Medium- and long-term results of jejunal pouch reconstruction after a total and proximal gastrectomy. Surg Today 2007;37:754-761.

-35 Adachi S, Inagawa S, Enomoto T, et al: Subjective and functional results after total gastrectomy: prospective study for longterm comparison of reconstruction procedures. Gastric Cancer 2003;6:24-29.

36 Kameyama H, Nashimoto A, Yabusaki H, et al: Reconstruction after proximal gastrectomy: comparison with single loop jejunal interposition and jejunal pouch interposition (in Japanese with English abstract). J Jpn Surg Assoc 2004;65:2294-2298.

>37 Iwata T, Kurita N, Ikemoto T, et al: Evaluation of reconstruction after proximal gastrectomy: prospective comparative study of jejunal interposition and jejunal pouch interposition. Hepatogastroenterology 2006; 53:301-303.
38 Hoshikawa T, Denno R, Ura H, et al: Proximal gastrectomy and jejunal pouch interposition: evaluation of postoperative symptoms and gastrointestinal hormone secretion. Oncol Rep 2001;8:1293-1299.

39 Okino T, Kuramoto K, Kimura Y, et al: Comparative studies between esophagogastrostomy and jejunal pouch interposition after proximal gastrectomy for early gastric cancer (in Japanese with English abstract). J Jpn Surg Assoc 2008;69:13-19.

40 Ueno M, Iwahashi M, Nakamori M, et al Complication of jejunal pouch interposition after proximal gastrectomy: case report Hepatogastroenterology 2004;51:916-918.

41 Katsube T, Konno S, Hamaguchi K, et al: Complications after proximal gastrectomy with jejunal pouch interposition: report of a case. Eur J Surg Oncol 2005;31:1036-1038.

42 Ikeda M, Ueda T, Yamagata K, et al: Reconstruction after distal gastrectomy by interposition of a double-jejunal pouch using a triangulating stapling technique. World J Surg 2003;27:460-464.

43 Iesato H, Ohya T, Ohwada S, et al: Jejunal pouch interposition with an isoperistaltic conduit as a pyloric ring substitute after standard distal gastrectomy: a comparison with the use of an isoperistaltic conduit. Hepatogastroenterology 2000;47:756-760.

44 Miwa K, Kinami S, Sahara H, et al: Jejunal pouch interposition and distal gastrectomy (in Japanese with English abstract). J Jpn Surg Soc 1997;98:560-564.
45 Nomura E, Shinohara H, Mabuchi H, et al: Postoperative evaluation of the jejunal pouch reconstruction following proximal and distal gastrectomy for cancer. Hepatogastroenterology 2004;51:1561-1566.

46 Rehnert T, Buhl K: Techniques of reconstruction after total gastrectomy for cancer. Br J Surg 2004;91:528-539.

$\checkmark 47$ El Halabi HM, Lawrence W Jr: Clinical results of various reconstructions employed after total gastrectomy. J Surg Oncol 2008; 97:186-192.

48 Tsuji H, Andoh S, Sakakibara K: The clinical evaluation of vagus nerve preserving gastric operation with D2 lymph node dissection for early and advanced gastric cancer (in Japanese with English abstract). Jpn J Gastroenterol Surg 2003;36:78-84.

49 Nakane Y, Akehira K, Okumura S, et al: Jejunal pouch and interposition reconstruction after total gastrectomy for cancer. Surg Today 1997;27:696-701.

50 Takeshita K, Saito N, Saeki I, et al: Proximal gastrectomy and jejunal pouch interposition for the treatment of early cancer in the upper third of the stomach: surgical techniques and evaluation of postoperative function. Surgery 1997;121:278-286.

51 Yoo CH, Sohn BH, Han WK, Pae WK: Proximal gastrectomy reconstructed by jejunal pouch interposition for upper third gastric cancer: prospective randomized study. World J Surg 2005;29:1592-1599. 